\title{
RESULTS OF EARLY INTERVENTION IN THE BABY WITH CEREBRAL MOTOR DISTURBANCE
}

\author{
S. H. IRWIN-CARRUTHers, Nat. Dip. Physio. (Pret.), Dip. Physio. Ed. (Pret.)*
}

\section{SUMMARY}

The results of a study comparing the early and late treatment of babies with cerebral motor disturbance are discussed. Criteria for diagnosis must be established before tests can begin. It would appear that early intervention results in marked improvement but more surveys are necessary to provide convincing evidence.

In recent years much has been written on the importance of early intervention in the treatment of cerebral motor disturbances. The term "cerebral motor disturbance" has replaced cerebral palsy and denotes a movement disorder which has developed as a result of brain damage. By "early intervention" we mean treatment started as early as possible within the first year of life and in any case at less than six months of age. In this country, we have not gone as far as in the United States where neurodevelopmentally trained

* Senior lecturer and Acting Head of Department, University of Stellenbosch and Tygerberg Hospital.

† Paper delivered at SASP Congress held in Pretoria March 1981.

Received 1 May 1981.

\section{OPSOMMING}

Die resultate van 'n studie wat vroeé en laat behandeling van babas met serebraal-motoriese versteuring vergelyk, word bespreek. Kriteria vir diagnose moen vasgestel word voor toetsing begin. Dit wil voorkom dat vroeé behandeling duidelike verbetering meebring. maar meer ondersoeke is nodig om oortuigende feite aan die lig te bring.

therapists are invading the incubators in the pre-term units.

Early intervention presupposes early diagnosis, which may be easy in the severely affected child but very difficult in the more moderately affected young baby. Several workers in the field of early intervention have been criticised on the grounds that their criteria for diagnosis may not exclude infants whose symptoms might have cleared spontaneously. Vojta, in particular, has come under criticism because in his clinic diagnosis is made on the grounds of seven reflexes, more than one of which bears his name and all of which are assessed subjectively for a degree of abnormality.

Köng $(1960,1975)$ has suggested six indications for early treatment:

- An obligatory abnormal pattern - from birth.

- Very low tone with no head control by three months. 
Even slight opisthotonus after three months.

Obligatory asymmetry after four months.

Slight (doubtful) abnormalities which become more pronounced in upright positions or suspension.

- Slight (doubtful) abnornalities in the presence of feeding problems.

Even using these criteria we cannot be certain that we are not including infants who may develop normally without intervention.

Even if we are happy with the diagnostic criteria, can we claim to have proven that early treatment on neurodevelopmental lines is necessary or that it gives better results? Bobath $(1967,1972)$ puts forward six reasons for early intervention:

- The adaptabilty of the infant brain.

- Prevention of reinforcement of abnormal postural patterns.

- Prevention of secondary contractures and deformities.

- Necessity for normal sensorimotor experience in building up normal postural patterns.

- The effect of normal sensorimotor experience on the acquisition of intellectual skills.

- The relative ease of implementing treatment techniques in the young baby.

Touwen (1979) considers all these factors to be valid, but points out the lack of convincing evidence of the beneticial results of early treatment. The very few published studies (Köng, 1966; Wright and Nicholson, 1973; Scherzer et al., 1976; lrwin-Carruthers, 1979) give conflicting evidence. Why is this?

When one looks at the problems encountered in conducting a controlled trial, the difficulties do appear insurmountable.

\section{PFOBLEMS OF ESTABLISHING CRITERIA FOR SELECTION}

In order to conduct a controlled trial one should have two comparable groups of children, the only difference between the groups being the age at which treatment was instituted. Invariably the early-treated group contains comparatively more severely affected children, since children showing obvious signs are likely to be diagnosed at an earlier age. Figure 1 shows the discrepancy between the two groups of early-treated and late-treated children for 43 White children seen at Tygerberg Hospital between July and December 1980.

If random sampling is used to determine the population, the bias between the two groups would most probably increase.

ln order to reach statistical significance it would be necessary to include all the children of other race groups, which would immediately result in large numbers of exclusions on grounds of irregular attendance for treatment. Significant mental retardation would also be grounds for exclusion, but this is very difficult to determine in a young baby.

\section{PROBLEMS OF ESTABLISHING CRITERIA FOR EVALUATION OF RESULTS}

Touwen (1979) makes a plea for therapists to document their criteria for determining results of treatment. Although spasticity as such can be measured objectively, the degree of spasticity does not necessarily correlate with functional ability and, in any case, it would not be advisable to subject a young child to the testing procedures involved. Esposito (1978) states that the aim of early intervention is to prepare the child for maximal physical, intellectual, emotional and social development to his full potential within the limits of his handicap. Thus we are trying to assess function rather than postural tone. The most obvious result of early treatment

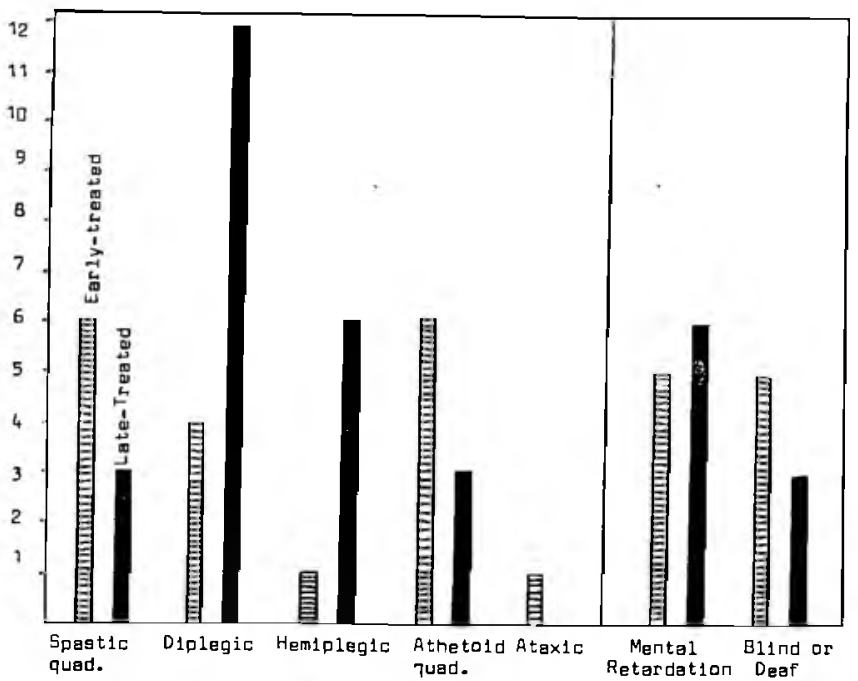

Fig. 1. Degree of involvement and associated handicaps.

to all those of us who are able to implement it is the quality of movement obtained, namely the presence of more normal patterns of movement and fewed abnormal ones. It is almost impossible to grade quality on a quantitative scale; even if such a scale cous be devised, the assignment of a grade cn that scale $w_{-} u_{i}$ be subjective.

The most obvious sign of improvement to bcth doctors and parents is the acquisition of functionai abilities, such as the ability to sit unsupported, get to sittin un- $^{-}$ aided, crawl, stand up and walk. This can be charte:-, although some problems will be encountere:

- Bias in parent-interpretation.

- Avoidance of certain devel pment:il wivites ior therapeutic reasons.

- Omissions of any assessment of the quai,ty er p:ttern of movement involved.

In the absence \& $\because \ldots$ criterii type of evaluation for results of our first comparative series.

\section{DISCUSSION OF RESULTS}

During the period April 1975 to April 15/0, 2is children with proven or suspected cerebint mutui turbances were referred to the physiothernpy ciepintment of Tygerberg Hospititl. Oi these, $20 \mathrm{i}$ ih.l......... found to have a degree of motor impairment sufiticient to warrant treatment. Of these only 93 have been . $b$. 8 to attend for regular treatment. 't he ie. S sit. wit. have precluded regular treatment oi the iemaizi. children are the subject of ancther sir.e, nd $\mathrm{ni}$ not be discussed in detail here but appro imateiy. ne third were children who live at a distence n $n$ treated by means of a home programme $: n$. peri: reassessment, approximately one third were $\mathrm{e}^{\mathrm{E}}=\mathrm{E} \cdot \mathrm{C}$ from other centres or therapists an. were ic..ie. treatment under their care, and the rest of the hilitien were lost to treatment through local conditions.

Of the 93 children who attende! rejularly, 23 were excluded from the present study because they were under nine months of age at the time of the anaiys.s These were all Coloured chiliren and attende! irre-ularly thereafter, so that their exclusion becrme peim: nent. This left 70 children, 15 of whom were referred for 
physiotherapy at six months of age or lcss (who will be designated the early-treated group) and 55 of whom were referred for therapy at more than six months of age (who will be designated the late-treated group). A further 42 children were excluded from the late-treated group on grounds of a significant mental handicap which might have affected the results of treatmont. No similar exclusion was made from the early-treated group, three of whom have a significant mental handicap.

In the early-treated group the predominant initial sign was retraction, i.e. increased extensor tone in the neck and shoulder musculature, which varied in degree from a moderate head-lag with inability to eye-track downwards to total opisthotonus. Six children presented with more than one sign; the other signs included asymmetry (with a persistent asymmetrical tonic neck reflex), fisted hand, "floppiness" and poor contact with the environment.

In the late-treated group the main complaint at the time of referral was of delay in the achievement of gross motor milestones, although all the mothers recounted several signs which they had noted at various earlier ages.
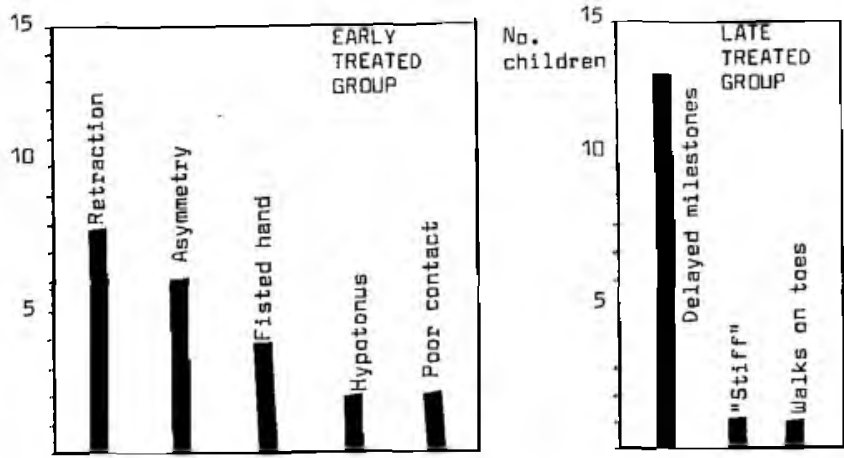

Fig. 2. Predominant sign at time of referral.

In the early-treated group, the mean age at which signs were first noticed was 3,33 months of age; the mean age of referral was 4,57 months of age. All but five of these babies were, as a result of their perinatal histories, being followed up by the Department of Paediatrics at Tygerberg Hospital and were referred immediately that signs were noted. In 4 icases the mother delayed taking the infant to a doctor and in one instance the delay was caused by initial referral via a general practitioner and a paediatrician in private practice. In all cases, however, the delay in referral was minimal.

Without exception, every child in the late-treated group could be classified as an at-risk infant and $62 \%$ of this group had been seen regularly by medical practitioners. An analysis of the children seen regularly at Tygerberg Hospital showed 2 who attended the premature follow-up clinic, 4 who attended neurosurgical follow-up after insertion of a shunt and 2 who attended regularly for general health problems. Despite this, in $92 \%$ of cases it was the mother who had pressed, usually repeatedly, for further investigation and treatment. The mean age at which the mother had first noted signs was 5,31 months and the mean age by which she was convinced something was wrong, despite assurance to the contrary, was 10,10 months; despite this the mean age of referral was 21,15 months. It must, however, be pointed out that this rather high age of referral was due to the extremely late age of referral of one or two children; in $38 \%$ of the children in this group referral was in fact made betwecn eight and twelve months of age.
High risk

Seen regularly at clinics Referred by doctor

Treatment requested by mother

Age at referrel: $8-12$ months

13-18 months

19-24 months

25-30 manths

$31-36$ manths

$>36$ manths

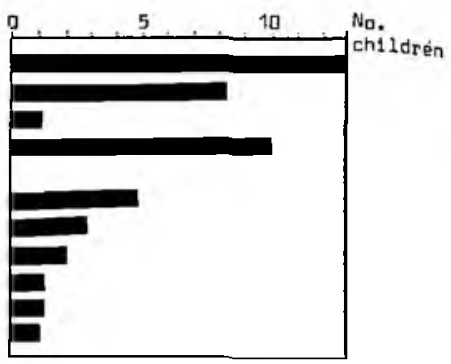

Fig. 3. Referral of late-treated group.

There is a fairly close correlation between diagnoses in the two groups, with spastic diplegia predominating in both groups. In all cases this spastic diplegia was related to prematurity with low birth weight.

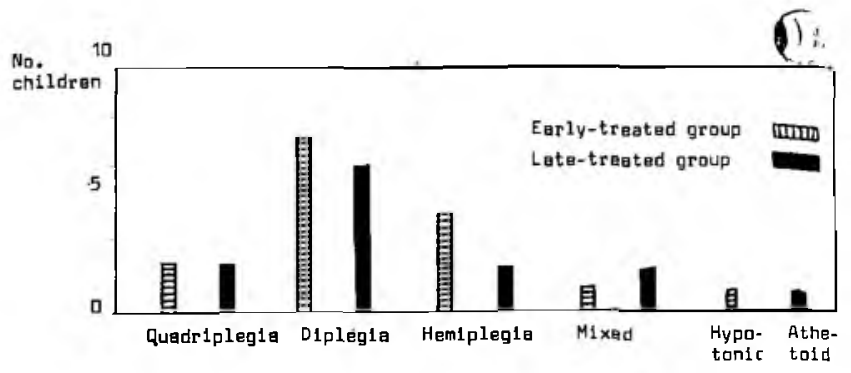

Fig. 4. Diagnosis.

Figurc 5 compares the dates at which gross motor activities were achieved in the two groups of children. It is necessary to define these gross motor activities if they are to form adequate criteria for judging results. Sitting implies maintaining the sitting position on the floor unsupported when placed in a position as close to long-sitting as possible, with or without arm-support.

Sitting up implies getting from prone or supine into the sitting position unaided.

Crawling implies reciprocal crawling on hands and knees (the American equivalent is creeping).

Standing up implies pulling to standing and maintaining the standing position, with or without holding on.

Walking implies walking unaided, without any form of support.

The early-treated group achieved unsupported sitting at a mean age of 8,53 months, were able to sit up from prone or supine at 10,36 months, were crawling at an average age of 10,36 months, pulling up to stand- ing at 12,15 months and walking independently at 15,03 months. These achievements compare very favourably with those of normal children and contrast strongly with the very delayed acquisition of gross motor activities in the late-treated group.

What these figures cannot convey is the quality of motor patterns. The children in the late-treated group show far more markedly abnormal patterns of co-ordination than those in the early-treated group. It seems logical to assume that treatment from a very early age will give favourable results.

The young infant seldom has very strong spasticity or tonic reflex activity and, since his sensorimotor experience is limited, he has not yet learnt to use abnormal patterns for function. Since the motor patterns which he requires are, at this age, relatively few and simple, it is easier to teach his mother how to handle him throughout 24 hours of the day in such a way 
as to provide him with normal sensorimotor experience and counteract the development of spasticity and of abnormal postural patterns.

Sitting
Sitting up
Cratiing
Standing uf
Salking

Fig. 5. Achievement of gross motor activities.

Figure 6 shows the present milestones achieved by the children in the two groups. All the children in the early-treated group are able to sit unsupported, sit up unaided, crawl and pull to standing. All but one can walk independently. The one child who cannot walk is a severely affected quadriplegic with mental retardation and, although his achievenents to date have been remarkable it is unlikely that he will ever walk unaided. There has been less change in the motor abilities of the late-treated group, all of whom are nuch older. The fact that $38 \%$ of this group were referred for treatment between the ages of 8 and 12 months would seem to lend support to the view that optimum results can only be obtained if treatment is institued within the first six months of life.

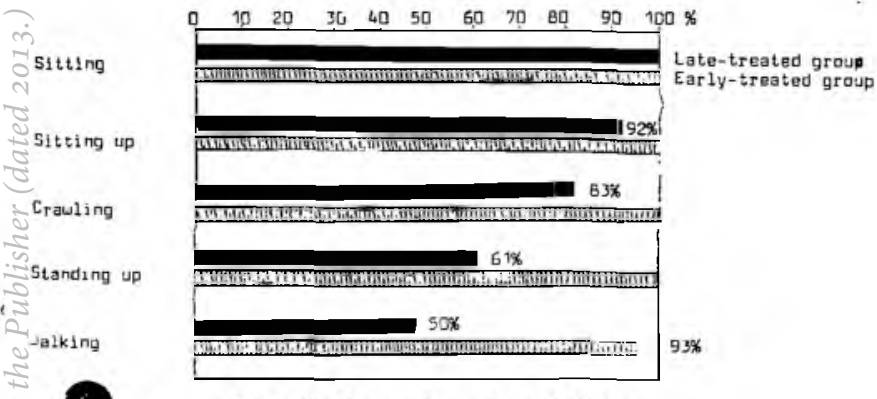

Fig. 6. Present motor abilities.

With early treatment it appears possible to reduce severe spasticity to moderate spasticity and more moderate signs to slight disabilities. To date the best results have been obtained with the spastic diplegics.

Good results have also been obtained with the hemiplegic children but, once they are running around, their abnormal patterns tend to increase slightly as a result of associated reactions. It is interesting to note, on further analysis, that the mean age of walking independently for the hemiplegic children in the early-treated group, was at 17,83 months, considerably later than that for the group as a whole. A spastic quadriplegic with athetosis, on the other hand, walked at 12 months.
Of the carly-treated group $60 \%$ are in regular nursery school or school; most of these are mild diplegics. In the carly-treated group $33 \%$ are in cerebral palsy schools, whereas $83 \%$ of the late-treated group need the special care of a cerebral palsy school. Two of the late-treated group died of shunt complications.

According to Arens and co-workers (1978) as well as from our own experience there does not appear to be any significant decrease in the incidence of cerebral palsy in South Africa. In view of this everything possible must be done to prepare these children for an independent and productive role within the community. If we believe that early intervention plays a decisive role in the eventual result we must be able to show proof of the results of early treatment. Although the contrast between the achievements of the early- and late treated groups in the survey is clear, the numbers of children involved are too small to claim statistical significance. Further surveys of carefully selected comparable groups are necessary, throughout the country, if we are to convince ourselves as well as the medical profession of the necessity for early treatment by physiotherapy.

\section{References}

Arens, L. J., Molteno, C. D., Marshall, S. R., Robertson, W. I. and Rabin, J. (1978). Cerebral Palsy in Cape Town - a comparative 12-year retrospective study. S. Afr. Med. J., 53, $319-324$.

Bobath, B. (1967). The very early treatment of cerebral palsy. Dev. Med. Child Neurol. 9, 373-390.

Bobath, B. and K. (1972) in: Physical Therapy services in the developmental disabilities. Ed. Pearson, PH. and Williams, C. E. Charles, C. Thomas. Springfield. p $101-112$.

Crow, B. M. (1973): Abnormal neurologic signs in the first year of life (letter to the editor). Dev. Med. Child Neurol., 15, 690-691.

Drillien, C. M. (1972). Abnormal neurologic signs in the first year of life in low birthweight infants: possible prognostic significance. Dev. Med. Child Neurol., 14. $575-584$.

Esposito, R. R. (1978). Physician's attitudes towards early intervention. Phys. Ther., 58, 160-167.

Irwin-Carruthers, S. H. (1979). A comparative study of early- and late-treated children with cerebral motor disturbance. Newsletter of the S.A. Neurodevelopmental Ther. Assn., 3, (2) 6-10.

Köng, E. (1966). Very early treatment of cerebral palsy. Dev. Med. Child Neurol., 8, $198-202$.

Köng, E. (1975). Personal communication.

Scherzer, A. L., Make, V. and Ilson, J. (1976). Physical therapy as a determinant of change in the cerebral palsied infant. Padieatrics, 58, 47-52.

Touwen, B. C. L. (1979). What are we actually doing? Newsletter of the S.A. Neurodevelopmental Ther. Assn. 3, (2) 3 - 5 (translated and reprinted from Keypoint - Kontakblad van die studiegroep voor die Behandeling van patienten met cerebrale paresen, 1979).

Wright, T. and Nicholson, J. (1973). Physiotherapy for the spastic child: an evaluation. Dev. Med. Child Nerrol. 15, $146-163$.. 